\title{
Transition metal oxides/hydroxides nanoarrays for aqueous electrochemical energy storage systems
}

\author{
Zhiyi $\mathrm{Lu}^{\dagger}$, Xiaochao $\mathrm{Wu}^{\dagger}$, Ming Jiang, Junnan Wang, Junfeng Liu, Xiaodong Lei and Xiaoming Sun ${ }^{1 *}$
}

\begin{abstract}
The need for the development of efficient electrochemical energy storage devices with high energy density, power density and safety is becoming more and more urgent in recent years, and the key for achieving the outstanding performance is the suitable structural designing of active materials. Nanoarray architecture emerged as one of the most promising structures, as it can offer many advantages to boost the electrochemical performance. Specifically, this kind of integrated electrodes can provide a large electrochemically active surface area, faster electron transport and electrolyte ion diffusion, leading to substantially improved capacitive, rate and cycling performances. In this paper, we will review the recent advances in strategies for synthesis of materials with nanoarray architectures and their applications in supercapacitors and batteries.
\end{abstract}

\section{INTRODUCTION}

Energy is one of the most important topics in the 21st century. With the rapid depletion of fossil fuels and increasingly worsened environmental pollution caused by vast fossil-fuel consumption, it is highly demanded to make more efficient use of energy while seeking renewable and clean energy sources to enable the sustainable development of our society [1]. Developing advanced energy storage systems with high energy density, high power density and prominent cycling stability is one of the most effective ways for increasing the efficiency. Ellis et al. [2] have provided a comparison of the characteristics of several common energy storage devices, as shown in Fig. 1. Fuel cells and batteries usually possess higher energy density, while capacitors and electrochemical supercapacitors (SCs) deliver higher power density with a short response time [2,3]. As two important devices for electrochemical energy storage (EES), batteries and SCs have attracted a worldwide attention and realized wide practical application as power sources for portable electronics such as cell phones and laptops and have great potentials to completely power electric vehicles and to be used in large-scale electrical grids [4,5]. For safety concerns, aqueous supercapacitors and batteries are definitely more favorable because of the nonflammability of the electrolyte.
These two major charge storage systems (aqueous SCs and batteries) are different in energy storage and conversion mechanisms. SCs can essentially be classified into two types: electric double layer capacitors (EDLCs) and pseudocapacitors (PCs). The former storage mode is an electrostatic (physical) process with fast charge adsorption and separation at the interface between electrode and electrolyte. The latter is a chemical process involving redox reactions between electrode materials and electrolyte ions $[1,6]$. As a result, EDLCs can provide higher power densities but inferior energy densities, while PCs possess much higher energy densities with compromised power densities. These two types of SCs can be easily distinguished by either cyclic voltammograms (CV) or galvanostatic discharge (GD) behavior (shown in Fig. 2). For EDLCs, the $\mathrm{CV}$ curve is close to a classic rectangular shape and the GD curve is almost linear, while the CV curve is characterized by faradaic redox peaks and there are one or multiple platforms in GD curve for PCs [7]. For batteries, the shapes of $\mathrm{CV}$ and GD curves are quite similar to those of PCs.

Developing advanced electrodes with novel approaches and structures are critical for improving such electrochemical energy storage systems. In traditional process of lithium ion battery industry, the active material powder is painted on the metallic foil with the assistance of binder [8]. How-

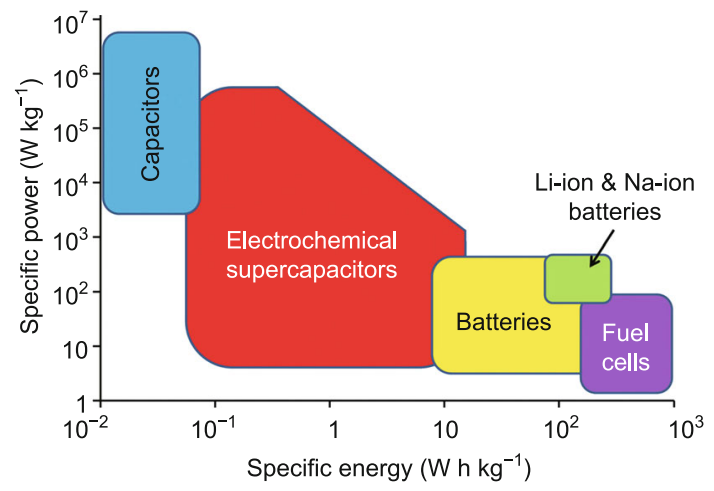

Figure 1 A Ragone plot of various energy storage devices. Reprinted with permission from Ref. [2] (Copyright 2014, Wiley-VCH).

State Key Laboratory of Chemical Resource Engineering, Beijing University of Chemical Technology, Beijing 100029, China.

$\dagger$ The first two authors contributed equally to this work.

* Corresponding author (email: sunxm@mail.buct.edu.cn) 

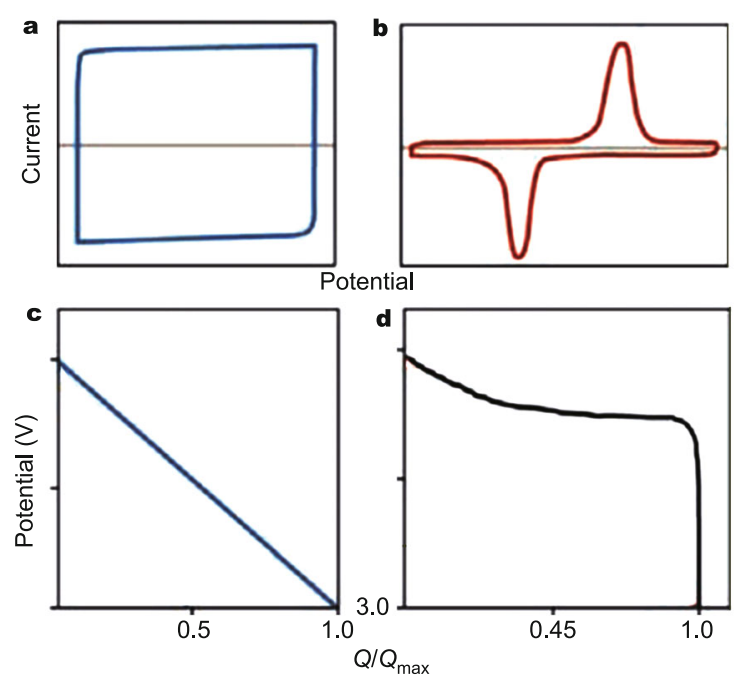

Figure 2 The electrochemical characteristics for distinguishing EDLCs and PCs. The CV curves of (a) EDLCs and (b) PCs; the GD curves of (c) EDLCs and (d) PCs. Reprinted with permission from Ref. [7] (Copyright 2014, AAAS).

ever, the loose contact between the materials and substrates will compromise the rate and cycling performances. Constructing the materials into nanoarray architectures, that is, some geometrically confined structures built with one dimensional (1D) or two dimensional (2D) primary nanostructures, which have similar dimension and size with similar orientations, has been proved effective to overcome the above problem [9-13]. In addition, these nanoarrays often exhibit fascinating properties, which are desirable for EES electrodes. It could provide large surface area and tunable free spaces for volume expansion, prevent agglomeration, facilitate the electron transfer rate and the penetration of the electrolytes into the whole electrode matrix, and strengthen the connection between active materials and substrates [2,14-17]. A schematic representation of an idealized nanoarrays electrode is shown in Fig. 3.

A lot of excellent reviews have reported various EES systems, which focus on different electrolyte types including organic electrolytes, aqueous phase and ionic liquids [1$5,14]$. Here in this paper we will summarize several fabrication processes of metal oxide and hydroxide materials with

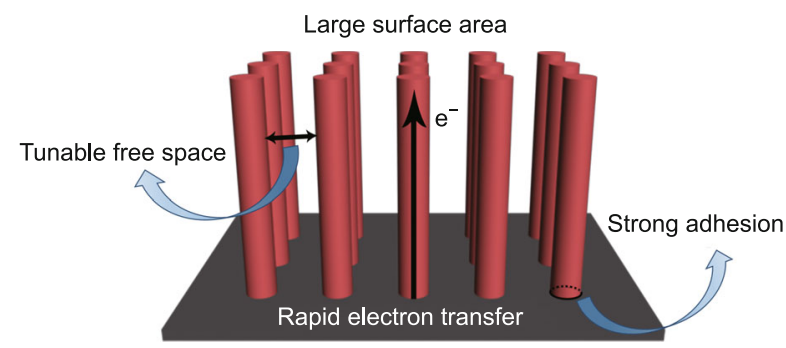

Figure 3 Schematic representation of a typical nanoarray. nanoarray architectures as well as their applications mainly in aqueous media. As well known, transition metal oxides and hydroxides are considered as the promising materials for next generation aqueous EES devices, owing to their multiple oxidation states that enable rich redox reactions for pseudocapacitance generation [18-20], while designing the electrochemically active materials into ordered nanoarrays architectures has been demonstrated effective for achieving higher performance. Thereby we would focus on the recent advances of nanoarray materials as high-performance electrodes for aqueous EES systems including SCs and batteries. At the last section, we put forward several possible research trends in the electrode architecture design to further improve the EES performance which may greatly outperform the state-of-art energy storage devices.

\section{SUBSTRATES AND SYNTHETIC METHODS}

First of all, it should be pointed out that one electrode is constructed with a current collector and active materials loaded on it. Thus, both the choice on current collector (or substrate) and the loading method will significantly determine the performance of final electrodes for given electrochemically active materials.

The substrate is a very important part for an electrode, especially for nanoarray based materials. It acts as not only a current conductor but also a template to grow ordered arrays. The crystal structure and the orientation of the substrates often play a vital role in the growth process of arrays [15]. Thus, the choice of the substrate will significantly affect the overall performance of the nanoarray materials.

The traditional substrate usually has a planar surface [20], which largely limits the contact area and the loading mass of the active materials. For this concern, 3D porous structures are more desirable to achieve larger surface area and high mass-loading. As an evolution of current collector, $\mathrm{Ni}$ foam is now widely used as the substrate, due to the large and uniform macropores, large supporting area and high electrical conductivity [21]. As we have estimated, for one piece of $\mathrm{Ni}$ foam $\left(0.5 \mathrm{~mm}\right.$ in thickness and $30 \mathrm{mg} \mathrm{cm}{ }^{-2}$ in weight, assuming the diameter of all primary microwires constructing the networks are $10 \mu \mathrm{m}$ in diameter), $30 \mathrm{~cm}^{2}$ of specific surface area can be achieved per $1 \mathrm{~cm}^{2} \mathrm{Ni}$ foam, due to the existence of pores with tens of micrometers in size.

The most obvious drawback of Ni foam is its instability in acid environment, which will dissolve the Ni foam and destroy the whole structure [22]. Thus, the Ni foam can only be used as substrate or current collector in neutral or alkali environments. Another issue is the pseudocapacitive contribution of the Ni foam surface, which might interfere the capacitance calculation, but as we have calculated, if the mass-loadings of the active materials are high enough 
to achieve a large areal capacitance (e.g. $\left.>4 \mathrm{~F} \mathrm{~cm}^{-2}\right)$, the inevitable substrate contribution $\left(\sim 0.2 \mathrm{~F} \mathrm{~cm}^{-2}\right)$ can be neglected [23]. In a word, Ni foam is a good current collector in alkaline or neutral electrodes as long as we subtract the possible capacitive contribution to get corrected specific capacitances of the active material [24]. As an alternative option of $\mathrm{Ni}$ foam, $\mathrm{Cu}$ foam has been used widely because of its high resistance to acidity and negligible capacitive contribution $[25,26]$.

The aforementioned substrates usually suffer from their high weights, which contribute a considerable proportion of the total weight of EES devices. Nevertheless, if heavy current collectors can be replaced by more lightweight materials, the effective SC for an entire capacitor device can be further improved $[8,27]$. Carbon materials are the most widely-used lightweight current collector for EES, such as carbon cloth [28], carbon fiber [29] and graphite foams [30], which have been prepared and indeed performed excellently as long as the carbon-oxide interface is constructed.

Some specific applications prompt interests on other specially designed electrodes. For instance, transparent electrode is a necessary component in many modern devices such as touch screens, LCDs, OLEDs, and solar cells [31-33]. The most common transparent substrates are tin and fluorine doped indium oxide (ITO and FTO), which possess the advantages of innate transparency $(\sim 90 \%$ in visible region), high electrical conductivity $\left(\sim 10^{4} \mathrm{~S} \mathrm{~cm}^{-1}\right)$, and chemical inertness [34]. However, They have certain problems, mainly centered on their scarcity of supply, and the ceramic nature [35]. Very recently, transparent electrodes based on metal nanowires [33] have been widely investigated, but their practicability needs further demonstration.

Every substrate has its corresponding loading method. As we mentioned before, the traditional method of preparing electrodes is painting the powder onto the current collector with assistance of binder. Compared to that, direct deposition or growth of electrochemically active materials onto conductive substrate is obviously more effective for achieving intimate contact between the current collector and the energy storage material. It is usually organized by electrochemical/hydrothermal transformation technique with or without the assistance of templates [36]. Common templates include anodized aluminium oxide (AAO) [37], anodized $\mathrm{TiO}_{2}$ nanotubes [38], $\mathrm{ZnO}$ nanorod template [39] and some track-etched polymer templates [40].

It should be noted that hybrid nanoarrays can also be constructed by some template-free electrochemical methods, which is more facile, cost-effective and environmental friendly. Commonly chemical vapor deposition (CVD) [41] is used for controllable fabrication of highly ordered nanostructure on substrate by gas-solid reaction, while chemical bath deposition and hydrothermal method [42, 43] are two typical wet means. Some examples including large area $\mathrm{MnO}_{2}$ nanowire $(70-100 \mathrm{~nm}$ in diameter and $1.5 \mu \mathrm{m}$ in length) arrays grown on fluorine-doped tin oxide coated glass [44], mesoporous (2-5 $\mathrm{nm}$ in pore-size) $\mathrm{NiCo}_{2} \mathrm{O}_{4}$ nanosheets loading on $\mathrm{Ni}$ foam [21], and porous (10-200 $\mathrm{nm}$ in diameters) $\mathrm{Ni} / \mathrm{Co}(\mathrm{OH})_{2}$ nanoflake films $(20$ $\mathrm{nm}$ in thickness) by a two-step electrodeposition process on Ni foam [45] have been reported.

Hydrothermal synthetic strategies on aqueous systems are considered as simple and powerful routes and recently become more and more popular in fabricating ordered nanoarray structures. This method relies on the chemical reactions and solubility changes of substances in a sealed heated aqueous solution above ambient temperature and pressure to grow nanocrystals [19]. The nucleation process on the surface of substrate is quite slow, which avoids the mixed and disorderly arrangement. The hydrothermal method has many advantages: i) this route is very versatile because the hydrothermal process occurs on a variety of materials, such as $\mathrm{Ni}(\mathrm{OH})_{2}[46], \mathrm{MnO}_{2}$ [47], $\mathrm{Co}(\mathrm{OH})_{2}$ [22,48], $\mathrm{FeOOH}[49], \mathrm{Cu}(\mathrm{OH})_{2}$ [50], $\mathrm{ZnO}$ [51], $\mathrm{V}_{2} \mathrm{O}_{5}$ [52]; ii) the reaction parameters can be easily controlled including temperature, time and concentration, which would result in different morphologies, porosity and compositions of the final products $[19,53]$; iii) multiple hydrothermal processes can be employed to grow hierarchical nanoarray structures with different components $\left(\mathrm{Co}_{3} \mathrm{O}_{4} @ \mathrm{NiO}\right.$ [42,43], $\mathrm{TiO}_{2}$ [54], $\mathrm{Ni}_{3} \mathrm{~S}_{2} @ \mathrm{MoS}_{2}$ [55], $\mathrm{Co}_{3} \mathrm{O}_{4} @ \mathrm{MnO}_{2}$ [56], $\mathrm{ZnO}$ [57], $\mathrm{Co}_{3} \mathrm{O}_{4} @ \mathrm{Fe}_{2} \mathrm{O}_{3}$ [58]), which offer an even higher porosity and mass-loading of the active layer.

\section{STRUCTURAL ADVANTAGE OF NANOARRAY MATERIALS AS EES ELECTRODES}

\section{Carbon nanoarrays for electrodes}

Carbon materials are regarded as the most promising electrode materials for industrialization. The energy storage mechanism of carbon materials belongs to the EDLCs, which is mainly originated from the accumulation of electric charges across the electrode/electrolyte interface $[59,60]$. The most important factors influencing their electrochemical performance are the specific surface area and pore-size distribution $[14,61,62]$. The usual form of ordered carbon-based nanoarray materials is carbon nanotube arrays (CNTAs) [63] which possess highly-ordered pore structures and high effective specific surface area. The ideal illustration of the CNTAs is shown in Fig. 4. The conductive channels and the one-dimensional structures in the CNTAs facilitate the ion and electron transportation and provide improved charge storage/deliver properties, which are highly desirable for high-rate applications $[64,65]$. Lat- 


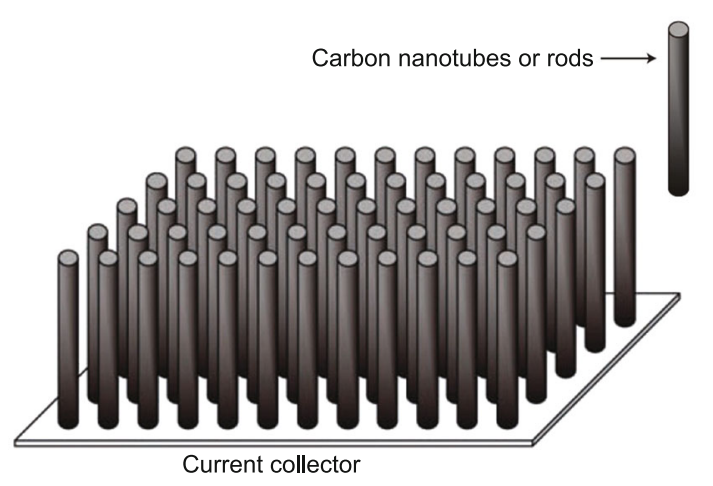

Figure 4 Ideal illustration of the CNTAs direct grown on current collector. Reprinted with permission from Ref. [4] (Copyright 2008, Nature Publishing Group).

est report also demonstrated that highly porous graphene film could also be constructed by template-dependent method and showed promising performance for SCs [66]. In order to improve the specific capacitance of the CNTAs, researchers introduced pseduocapacitive materials which possessed much higher capacitances into the 3D network [63]. Fan et al. [41] reported a novel strategy to prepare 3D CNTA-graphene sandwich (CGS) structures with CNTAs grown in between the graphene layers by co-catalyst CVD approach. The SC based on CGS exhibits a specific capacitance of $385 \mathrm{~F} \mathrm{~g}^{1}$, much higher than that of the counterpart.

\section{Pseudocapacitive nanoarray materials for electrodes}

\section{One dimensional nanoarray materials}

One dimensional (1D) structured nanoarrays, including nanowires, nanorods and nanotubes are the basic structures in nanoarrays $[15,67]$. The $1 \mathrm{D}$ nanostructure can offer a direct pathway for electron transfer and the high aspect ratio can facilitate the electrolyte penetration and maximize the utilization of the active materials $[19,68]$.

Our group has employed a facile hydrothermal reaction followed by a calcination process to fabricate $\mathrm{NiO}$ nanorod arrays [69], which showed a combination of ultrahigh specific capacitance, high power density and good cycling stability. As schemed in Fig. 5, the slim rod morphology reduced the diffusion distance through which the electrolyte had to penetrate to less than $10 \mathrm{~nm}$ [70], and thereby increasing the active surface area for insertion and extrusion of $\mathrm{OH}^{-}$and consequently maximizing the pseudocapacitance (Zone 1). Concurrently it also maximized the surface area exposed to the bulk solution, which enlarged the EDLC, as shown in the discharge curves (Zone 2). As a result, the measured capacitance was as high as $2018 \mathrm{~F} \mathrm{~g}^{-1}$, close to the theoretical value $\left(2573 \mathrm{~F} \mathrm{~g}^{-1}\right)$.

$\mathrm{Lu}$ et al. [44] have studied the effect of differenct structures on the electrochemical performance. They synthesized large-area $\mathrm{MnO}_{2}$ nanorod arrays (MONRAs) and herringbones (MOHBs) on FTO substrates by similar electrochemical methods. Although the MOHBs showed a larger surface area than the MONRAs, the MONRAs showed a better capacitive performance, indicating that vertically aligned nanorod array was more desirable because of the high electron transport rate, as shown in Fig. 6.

\section{Two dimensional nanoarray materials}

Two-dimensional (2D) nanostructures, typically nanosheet, usually possess a thin thickness nature, thus inheriting the advantages of slim 1D nanostructures. Compared with 1D nanoarray, the active surface area of ultrathin 2D nanoarray materials is smaller, but the contact area of the materials to the substrate is much larger, which leads to better electrical contact (shown in Fig. 7), thus beneficial for the electron transport and rate capability. Besides, the larger size of 2D nanostructure offers a higher loaded mass on
Figure 5 A schematic image showing how the $\mathrm{NiO}$ nanorod generates EDLC and pseudocapacitance. Reprinted with permission from Ref. [69] (Copyright 2011, Springer).

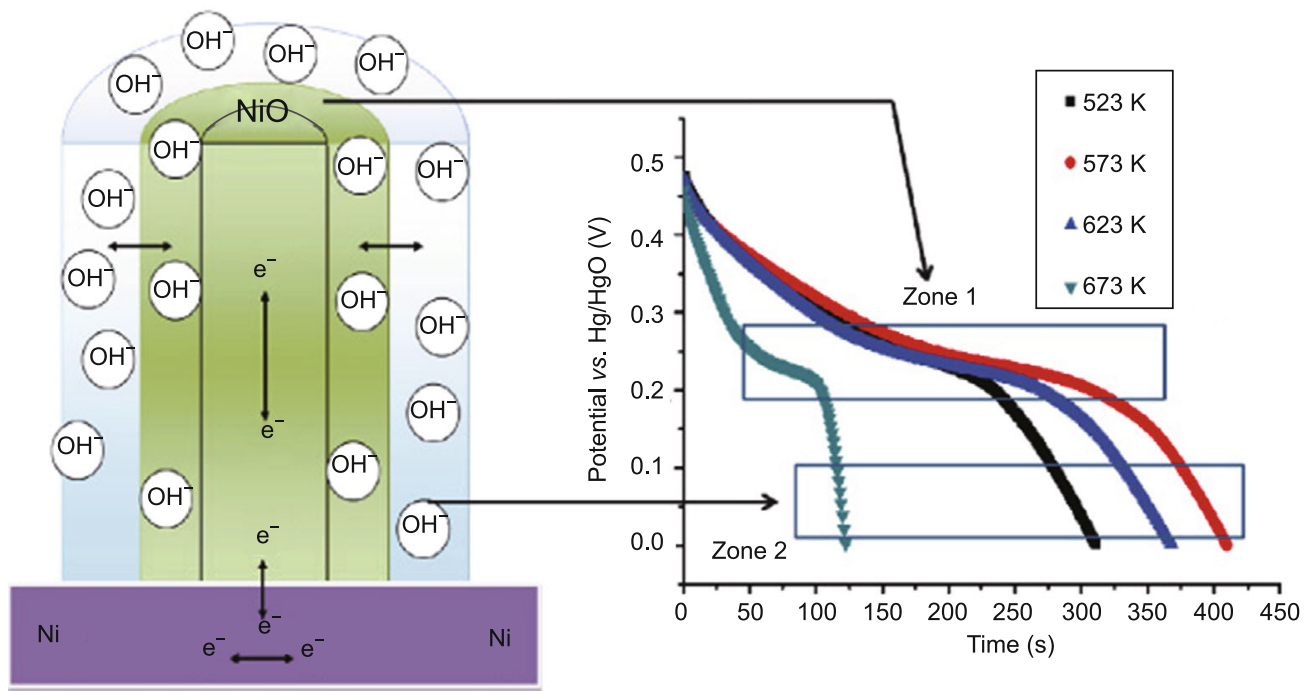




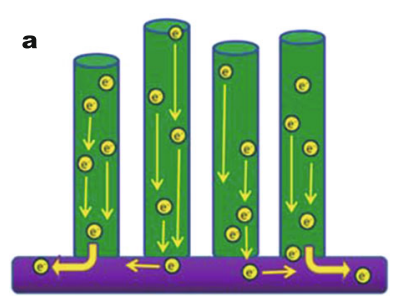

FTO Substrates

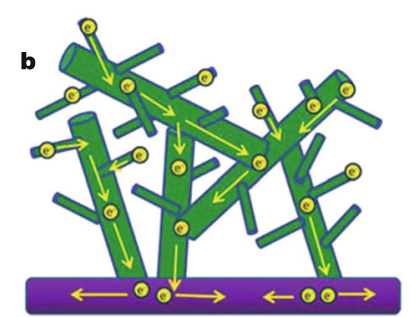

FTO Substrates
Figure 6 Schematic representation of the electron path on (a) MONRAs and (b) MOHBs electrodes. Reprinted with permission from Ref. [44] (Copyright 2011, The Royal Society of Chemistry).

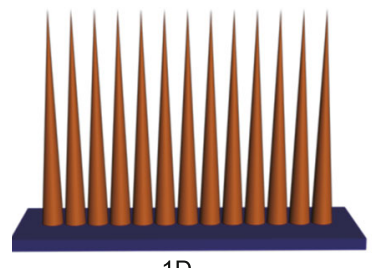

1D

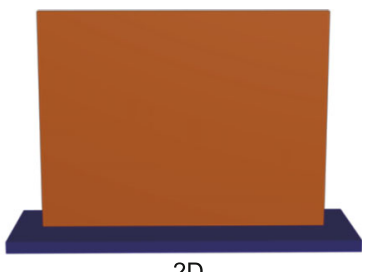

2D
Figure 7 The schematic of 1D and 2D nanoarray materials.

geometric area, which is beneficial to improve the areal capacitance [71].

Our group has developed a facile hydrothermal route to fabricate an ultrathin $\mathrm{Ni}(\mathrm{OH}){ }_{2}$ nanowalls film on $\mathrm{Ni}$ foam [46]. It is found that the extremely thin thickness $(\sim 6 \mathrm{~nm})$ of the nanowalls played an important role in yielding the ultrahigh capacitance by effectively shortening the proton diffusion distance and making the chemically active materials almost $100 \%$ usable for redox reaction. Meanwhile, it also provided additional EDLC at the interfaces, which endowed the $\mathrm{Ni}(\mathrm{OH})_{2}$ nanowalls with an ultrahigh capacitance of 2,675 $\mathrm{F} \mathrm{g}^{-1}\left(7.85 \mathrm{~F} \mathrm{~cm}^{-2}\right)$ and $96 \%-98 \%$ retention depending on the varied current density. Yuan et al. [72] and Zhao et al. [73] also found that $\mathrm{Co}_{3} \mathrm{O}_{4}$ and $\mathrm{MnO}_{2}$ with ultrathin nanosheet structures could also deliver ultrahigh capacitive performances, demonstrating the effectiveness of this structural design.

Layered double hydroxides (LDHs), which have a general formula of $\left[\mathrm{M}_{1-x}^{2+} \mathrm{M}_{x}^{3+}(\mathrm{OH})_{2}\right]^{x+}\left[\mathrm{A}_{x / n}^{n-} \cdot \mathrm{mH}_{2} \mathrm{O}\right]^{x-}\left(\mathrm{M}^{2+}\right.$ and $\mathrm{M}^{3+}$, the bivalent and trivalent metal cations, respectively; $\mathrm{A}^{n-}$, the charge-balancing anion of valence; $x=\mathrm{M}^{3+}$ / $\left.\left(\mathrm{M}^{2+}+\mathrm{M}^{3+}\right)\right)$, have attracted increasing interest from both academic and industrial angles due to their wide applications in various areas [74]. Recently, LDHs with vertically aligned structures have exhibited great potential in SCs [75-78]. Gu et al. [79] prepared a NiTi-LDH nanosheet film by a two-step hydrothermal process, which showed a high areal capacitance of $10.37 \mathrm{~F} \mathrm{~cm}^{-2}$ at $5 \mathrm{~mA} \mathrm{~cm}^{-2}$. To further improve the EES performance of $2 \mathrm{D}$ structure, creating holes in the nanosheets to increase the porosity is regarded as an effective method. Our group has fabricated a thin mesoporous cobalt carbonate hydroxide (MPCCH) nanosheet array by selectively etching the $\mathrm{Al}$ element of a CoAl-LDH thin film in highly concentrated $\mathrm{NaOH}$ solution [80]. The specific capacitance of the MPCCH could reach $1,075 \mathrm{~F} \mathrm{~g}^{-1}$ at $5 \mathrm{~mA} \mathrm{~cm}^{-2}$, which was much higher than that of the CoAl-LDH precursor. Further studies also confirmed the effectiveness of this structural design for LDHs. Chen et al. [81] have grew NiCo-LDH films on $\mathrm{Ni}$ foam with ultrathin nanosheets and porous nanostructures, which displayed a significantly enhanced specific capacitance $\left(2,682 \mathrm{~F} \mathrm{~g}^{-1}\right.$ at $\left.3 \mathrm{~A} \mathrm{~g}^{-1}\right)$. The possible formation mechanism of NiCo LDH is shown in Fig. 8.

\section{Hierarchical nanoarray materials}

For practical application of SCs, high areal capacitance of EES electrode is actively pursued, which requires a combination of high mass-loading and high utilization of electrochemically active material. In general, high mass-loading on conventional electrodes usually leads to an increase of "dead volume" in electrode materials which is not accessible to the electrolyte in the SC, and thus results in low utilization efficiencies of the materials. In this regard, hierarchical design of complex core-shell nanoarrays with porous structures is considered as an effective approach to simultaneously achieve high mass-loading and high utilization of the electrode material, because they not only provide large active surface area and short diffusion path lengths to electrons and ions, but also show a potential synergistic effect of each component, leading to high capacitance, low internal resistance, remarkable rate capability, and excellent stability [5,24,82-86].

According to the aforementioned advantages of hierarchical structure design, our team has synthesized 3D $\mathrm{Co}_{3} \mathrm{O}_{4} @ \mathrm{Co}_{3} \mathrm{O}_{4}$ and $\mathrm{Co}_{3} \mathrm{O}_{4} @ \mathrm{NiO}$ hierarchical nanoarrays electrodes for SC $[42,43,53]$. Thanks to the unique architecture, these hierarchical nanoarray electrodes showed excellent electrochemical performance, much better than the individual components $\left(\mathrm{Co}_{3} \mathrm{O}_{4}\right.$ nanosheet arrays and

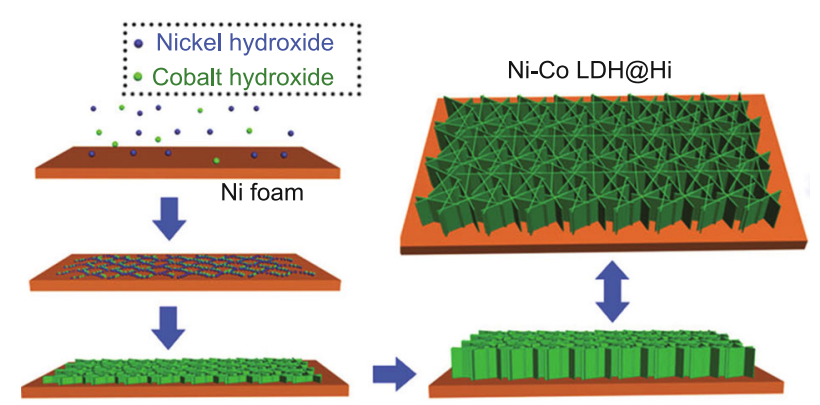

Figure 8 The possible formation mechanism of NiCo LDH hybrid films supported on Ni foam and the illustration scheme of the asymmetrical SCs. Reprinted with permission from Ref. [81] (Copyright 2014, WILEY-VCH). 
Table 1 Comparison of the capacity, mass loading and capacity retention of hierarchical structural nanoarray materials

\begin{tabular}{|c|c|c|c|c|}
\hline Materials & Specific capacitance $\left(\mathrm{F} \mathrm{g}^{-1}\right)$ & Areal capacitance $\left(\mathrm{F} \mathrm{cm}^{-2}\right)$ & Mass loading $\left(\mathrm{mg} \mathrm{cm}^{-2}\right)$ & Capacitance retention \\
\hline $\mathrm{Co}_{3} \mathrm{O}_{4} @ \mathrm{Ni}-\mathrm{Co}-\mathrm{O}[42]$ & $2098\left(5 \mathrm{~mA} \mathrm{~cm}^{-2}\right)$ & 24.95 & 12 & $96 \%$ (1000 cycles) \\
\hline $\mathrm{Co}_{3} \mathrm{O}_{4} @ \mathrm{NiO}[43]$ & $2033\left(5 \mathrm{~mA} \mathrm{~cm}^{-2}\right)$ & 39.6 & 19.5 & 100\% (1000 cycles) \\
\hline Hierarchical $\mathrm{Co}_{3} \mathrm{O}_{4}[53]$ & $715\left(5 \mathrm{~mA} \mathrm{~cm}^{-2}\right)$ & 5.44 & 7.6 & 100\% (1000 cycles) \\
\hline $\mathrm{Ni}_{3} \mathrm{~S}_{2} @ \mathrm{Ni}(\mathrm{OH})_{2}[83]$ & $1277\left(2 \mathrm{mV} \mathrm{s}^{-1}\right)$ & 4.7 & 3.7 & 99.1\% (2000 cycles) \\
\hline $\mathrm{CoO} @ \mathrm{Ni}(\mathrm{OH})_{2}[82]$ & $798\left(1.67 \mathrm{~A} \mathrm{~g}^{-1}\right)$ & 2.7 & 3.4 & 95\% (2000 cycles) \\
\hline $\mathrm{Co}_{3} \mathrm{O}_{4} @ \mathrm{MnO}_{2}[87]$ & $480\left(2.67 \mathrm{~A} \mathrm{~g}^{-1}\right)$ & 0.56 & 1.2 & $97.3 \%$ (5000 cycles) \\
\hline $\mathrm{NiCo}_{2} \mathrm{O}_{4} @ \mathrm{MnO}_{2}[88]$ & $1471\left(10 \mathrm{~mA} \mathrm{~cm}^{-2}\right)$ & 2.06 & 1.4 & 88\% (2000 cycles) \\
\hline $\mathrm{Co}_{3} \mathrm{O}_{4} @ \mathrm{NiO}[24]$ & $853\left(2 \mathrm{~A} \mathrm{~g}^{-1}\right)$ & 2.56 & 3 & $95 \%$ (6000 cycles) \\
\hline $\mathrm{SnO}_{2} / \mathrm{MnO}_{2}[89]$ & $800\left(1 \mathrm{~A} \mathrm{~g}^{-1}\right)$ & & & $83 \%$ ( 2500 cycles) \\
\hline $\mathrm{NiCo}_{2} \mathrm{O}_{4}[90]$ & $1118\left(5.6 \mathrm{~mA} \mathrm{~cm}^{-2}\right)$ & 3.12 & 3 & $89 \%$ (2000 cycles) \\
\hline
\end{tabular}

nanowire arrays). The ultrahigh mass loading (12-20 $\mathrm{mg} \mathrm{cm}{ }^{-2}$ ) and thin morphologies of the electrode result in an ultrahigh areal capacitances up to $\sim 40 \mathrm{~F} \mathrm{~cm}^{-2}$, which is the highest among the reported values (Table 1), while the rate capability and cycling stability are well preserved.

This architecture design is also applicable for other pseudocapacitive materials. Liu et al. [87] have used 3D ordered amorphous carbon layers function as a sacrificial reactive template to anchor $\mathrm{MnO}_{2}$ nanostructures onto another metal oxide scaffolds, producing hierarchical hybrid nanostructure arrays for SC applications. The purposely built smart electrode made of $\mathrm{a} \mathrm{Co}_{3} \mathrm{O}_{4} @ \mathrm{MnO}_{2}$ nanowire array exhibits excellent electrochemical performance, much better than the individual parts. Mai et al. [91] also synthesized 3D multicomponent oxides, $\mathrm{MnMoO}_{4} / \mathrm{CoMoO}_{4}$ with high capacitance. Liu et al. [92] reported the synthesis of $\mathrm{MnO}_{2}-\mathrm{NiO}$ nanoflake-assembled tubular array on stainless steel substrate to function as pseudocapacitor electrode, which displays an areal capacitance that is four orders of magnitude higher than that of carbonaceous materials.

\section{APPLICATIONS OF NANOARRAY MATERIALS IN EES SYSTEMS}

A total EES system usually consists of two electrodes, an electrolyte, and a separator that electrically isolates the two electrodes [14]. In this section, we will review the applications of nanoarray materials in some common systems including symmetric supercapacitors (SSCs), asymmetric supercapacitors (ASCs) and batteries, and firstly we will define some terminologies as following.

The total capacitance $\left(C_{\mathrm{T}}\right)$ of the EES system can be calculated as Equation (1):

$$
\frac{1}{C_{\mathrm{T}}}=\frac{1}{C_{\mathrm{P}}}+\frac{1}{C_{\mathrm{N}}},
$$

where $C_{\mathrm{p}}$ and $C_{\mathrm{N}}$ are the capacitance of the positive and negative electrodes based on a three-electrode setup, respectively. For SCs, if the two electrodes are identical $\left(C_{\mathrm{p}}=\right.$ $C_{\mathrm{N}}$ ), the corresponding system is called a SSC and the total capacitance $C_{\mathrm{T}}$ will be one half of either one's capacitance. In other case, the positive and negative electrodes use different materials corresponding to ASCs, and $C_{\mathrm{T}}$ will depend on the relatively small value between $C_{\mathrm{p}}$ and $C_{\mathrm{N}}$ [64].

Energy and power densities are two crucial parameters for evaluating the electrochemical performance of SCs. The maximum energy $(E)$ and power densities $(P)$ of a SC can be obtained using Equations (2) and (3), respectively $[14,59]$ :

$$
\begin{gathered}
E=\frac{1}{2} C_{\mathrm{T}} V^{2}, \\
P=\frac{V^{2}}{4 R},
\end{gathered}
$$

where $C_{\mathrm{T}}$ is the total capacitance of the system; $V$ is the operating voltage, which is determined by the thermodynamic stability of an electrolyte and dependent upon the electrode materials; and $R$ is the equivalent series resistance. Therefore, in order to achieve excellent performance for a SC, it is of critical significance to find two SC electrodes with matched capacitances and simultaneously possess high capacitance, wide operating cell voltage, and minimum equivalent series resistance.

\section{Coupling nanoarray materials for SSCs}

The SSC is a common type in conventional EES system, which includes two same electrodes. The material screening is of great importance to assemble SSCs because the materials should be active in a wide range of potential. Up to now, only several materials have been successfully applied in SSCs, such as carbon [93], $\mathrm{MnO}_{2}$ [94] and $\mathrm{RuO}_{2}$ [95]. Since the scarcity and high cost of $\mathrm{RuO}_{2}$, carbon and manganese oxides have been widely investigated as cheap alternatives [96]. Reddy et al. [94] have assembled a SSC involving two $\mathrm{Au}-\mathrm{MnO}_{2} / \mathrm{CNT}$ electrodes, delivering high energy density and remarkable rate capability.

\section{Design of ASCs}

Assembling ASCs have been found to be an effective ap- 
proach to increase the energy density of SCs. The ASCs usually consist of two different-type electrodes, simultaneously offering the advantages of both SCs (rate, cycle life) and advanced batteries (energy density) [97]. Therefore, ASCs can make full use of the different potential windows of the two electrodes to provide a maximum operation voltage in the cell system, accordingly resulting in a greatly enhanced specific capacitance and significantly improved energy density $[47,98,99]$.

Materials with redox potentials above $0 \mathrm{~V}(v s$. normal hydrogen electrode) can be considered as positive materials, such as $\mathrm{MnO}_{2}, \mathrm{Co}_{3} \mathrm{O}_{4}$ and $\mathrm{Ni}(\mathrm{OH})_{2}$, as we have mentioned in the previous section. With regard to the negative materials, carbonaceous materials such as porous carbons, CNTs and graphene often act as electrodes with the working potential window below $0 \mathrm{~V}$ for ASCs [100]. Wu et al. [97] developed a high-voltage ASC based on graphene as negative electrode and $\mathrm{MnO}_{2}$ nanowire/graphene composite (MGC) as positive electrode in a neutral aqueous $\mathrm{Na}_{2} \mathrm{SO} 4$ solution as electrolyte. This ASC can be cycled reversibly in the high voltage region of $0-2.0 \mathrm{~V}$ and exhibits a superior energy density of $30.4 \mathrm{~W} \mathrm{~h} \mathrm{~kg}$. Z Zhou et al. [101] fabricated an ASC by using 3D CoO@Polypyrrole nanowires array as the positive electrode and activated carbon (AC) film as the negative electrode. This device has demonstrated high energy density of $43.5 \mathrm{~W} \mathrm{~h} \mathrm{~kg}^{-1}$ and outstanding cycling stability.

\section{Nanoarray materials for aqueous rechargeable batteries}

Different from ASCs, aqueous batteries consist two electrodes both with battery-type faradaic character. Hundreds of electrochemical redox couples have been proposed to construct rechargeable batteries [102,103]. Fig. 9 summarizes the working potential windows of various psedocapacitive materials in aqueous electrolyte [104], demonstrating that materials such as $\mathrm{Ni}(\mathrm{OH})_{2}, \mathrm{MnO}_{2}$ and $\mathrm{Co}_{3} \mathrm{O}_{4}$

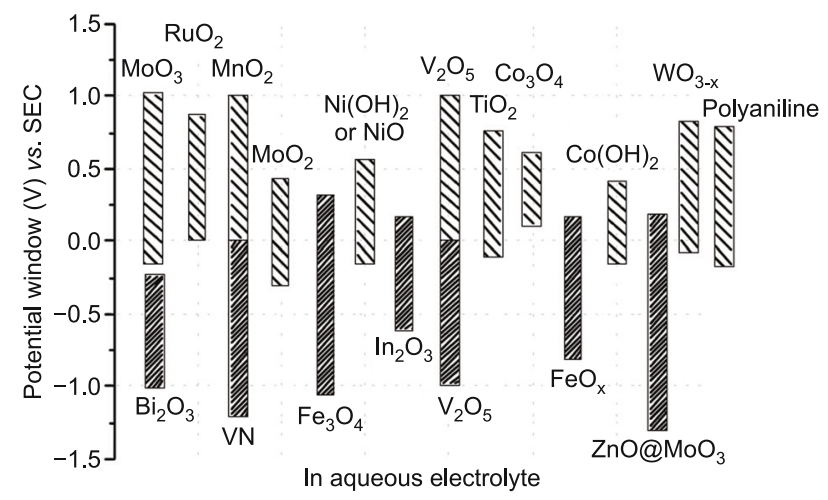

Figure 9 The working potential windows of various pseudocapacitive type materials in aqueous electrolyte. Reprinted with permission from Ref. [104] (Copyright 2011, Wiley-VCH). can be used as cathodes while $\mathrm{Bi}_{2} \mathrm{O}_{3}, \mathrm{In}_{2} \mathrm{O}_{3}$ and $\mathrm{FeO}_{\mathrm{x}}$ can be used as pseudocapacitive anodes. Although lithium-ion batteries are dominantly powering most of today's portable electronics due to the high efficiency and energy density, the high expense and possible unsafety originated from the flammability of organic electrolytes and high reactivity of Li containing materials are two major concerns for our daily life. Instead, aqueous rechargeable batteries (ARBs) with much higher power density and safety have attracted renewed interest as a possible alternative solution.

As an important part of ARBs, aqueous rechargeable lithium batteries (ARLBs) use lithium intercalation compounds as one or two electrodes based on redox reactions and a lithium-containing aqueous solution as the electrolyte [105]. Tang et al. [106] successfully prepared $\mathrm{LiMn}_{2} \mathrm{O}_{4}$ nanotube arrays with an exposed (400) planes by using multiwall carbon nanotubes (MWCNTs) as a sacrificial template. The hybrid material was used as cathode for ARLB, which delivers a high capacity of $110 \mathrm{~mA} \mathrm{~h} \mathrm{~g}^{-1}$ at $4.5 \mathrm{C}$ and presents very good capacity retention at superfast second-level charge and discharge rates. Besides this, his group has also devoted effort on anode materials. They coated a polypyrrole layer of 10-12 nm in thickness on a hybrid of $\mathrm{V}_{2} \mathrm{O}_{5}$ nanowires and MWCNTs [107], which was used as an anode material to construct an ARLB with almost no capacity loss after 500 full cycles.

Our group developed a facile hydrothermal method to fabricate hierarchical nanoarrays-based material for an alkaline battery. We synthesized a hierarchical $\mathrm{Co}_{x} \mathrm{Fe}_{3-x} \mathrm{O}_{4}$ nanoarray directly grown on conductive substrate, which is desirable for anode material [108]. After that we have designed an alkaline battery by pairing it with hierarchical $\mathrm{Co}_{3} \mathrm{O}_{4} @ \mathrm{Ni}-\mathrm{Co}-\mathrm{O}$ nanoarrays electrode as cathode material. The double hierarchical nanoarrays-based aqueous battery (shown in Fig. 10) delivered a high energy den-

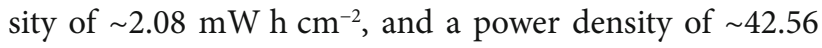
$\mathrm{m} \mathrm{W} \mathrm{cm} \mathrm{cm}^{-2}$ with less than $3 \mathrm{~min}$ for one charge-discharge cycle.

\section{CONCLUSIONS AND OUTLOOK}

The field of nanoarray materials has flourished in recent years. Due to their unique structure, the nanoarray materials show great promise in EES devices, especially for the transition metal oxides and hydroxides materials. The nanoarray architecture can provide a high surface area, high overall porosity and strong bonding between the active materials and the conductive substrate, which are beneficial to overcome common problems of particle strain and contact loss observed in bulk electrodes, resulting in high specific capacitance, remarkable rate capability and prominent cycling stability. In this review, several synthesis methods and some recent advances in designing and electrochemi- 


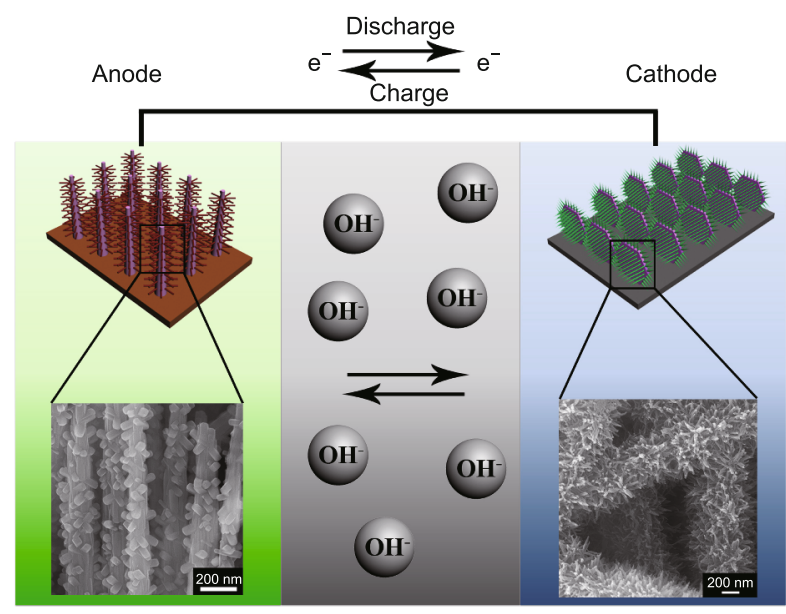

Figure 10 The schematic drawing of the double hierarchical nanoarrays-based aqueous battery. Reprinted with permission from Ref. [108] (Copyright 2014, Elsevier).

cal applications of nanoarray materials have been summarized. Despite the great progresses, how to further improve the electrochemical performance should be the key point which needs most of the researchers' efforts. Along this direction, several possible future trends are discussed herein.

SCs can provide high power density, superior rate capability, long cycling life. However, the relatively low energy density is mainly restricted by the narrow working potential of aqueous electrolyte. Since the energy density of a $\mathrm{SC}$ is proportional to the square of the operating voltage, increasing the operation voltage is regarded as a promising strategy to improve the energy density. Organic electrolytes (up to 2.5-3.0 V) and ionic liquids (up to $4 \mathrm{~V}$ ) are two ideal options, but they are limited by poor conductivity or high cost. Metal organic framework materials are able to retard the electrolysis of water, thus broadening the voltage window of aqueous electrolytes [109], which may provide a feasible strategy to enhance the energy density in the future.

Another strategy is to pursue high mass-loading of the active materials in a geometric area with high ultilization, leading to a high areal capacitance. In our previous studies, hierarchical structures are demonstrated effective to significantly improve the areal capacitance, but the mass-loadings still needs to be increased. Integrating active nanomaterials into the remaining free space in the hierarchical nanoarrays or into the interspace between neighboring arrayed nanostructures should be an effective approach by making full use of voids within the electrode. However, the attendant problems should be taken into consideration carefully. For instance, sufficient porosity of the hybrid structure (hierarchical structure with active nanomaterials) should be maintained for the electrolyte penetration, and the electric connection between the two components should be optimized.

In industry, the electrode of EES is always made by casting the active materials slurry onto current collectors, while the practical device using nanoarray electrodes is seldom. The synthetic method of nanoarrays is difficult to achieve in industrial level which limits its development. Actually, some excellent nanoarray EES devices have been developed. But the assembly technology and package engineering are also critical to maximize the energy storage performance. In a word, the nanoarray material is in its infancy, and there are still a lot of efforts to be devoted in the future.

Received 15 October 2014; accepted 30 October 2014; published online 8 December 2014

1 Liu C, Li F, Ma LP, et al. Advanced materials for energy storage. Adv Mater, 2010, 22: E28-E62

2 Ellis BL, Knauth P, Djenizian T. Three-dimensional self-supported metal oxides for advanced energy storage. Adv Mater, 2014, 26: 3368-3397

3 Winter M, Brodd RJ. What are batteries, fuel cells, and supercapacitors? Chem Rev, 2004, 104: 4245-4270

4 Simon P, Gogotsi Y. Materials for electrochemical capacitors. Nat Mater, 2008, 7: 845-854

5 Jiang J, Li YY, Liu JP, et al. Recent advances in metal oxide-based electrode architecture design for electrochemical energy storage. Adv Mater, 2012, 24: 5166-5180

6 Wu ZS, Zhou G, Yin LC, et al. Graphene/metal oxide composite electrode materials for energy storage. Nano Energy, 2012, 1: 107131

7 Simon P, Gogotsi Y, Dunn B. Where do batteries end and supercapacitors begin? Science, 2014, 343: 1210-1211

8 Zhou RF, Meng CZ, Zhu F, et al. High-performance supercapacitors using a nanoporous current collector made from super-aligned carbon nanotubes. Nanotechnology, 2010, 21: 345701

9 Wang WN, An WJ, Ramalingam B, et al. Size and structure matter: enhanced $\mathrm{CO}_{2}$ photoreduction efficiency by size-resolved ultrafine Pt nanoparticles on $\mathrm{TiO}_{2}$ single crystals. J Am Chem Soc, 2012, 134: 11276-11281

$10 \mathrm{Wu}$ W, Zhang S, Ren F, et al. Controlled synthesis of magnetic iron oxides@SnO $\mathrm{S}_{2}$ quasi-hollow core-shell heterostructures: formation mechanism, and enhanced photocatalytic activity. Nanoscale, 2011, 3: 4676-4684

11 Cheng CW, Fan HJ. Branched nanowires: Synthesis and energy applications. Nano Today, 2012, 7: 327-343

12 Bruce PG, Scrosati B, Tarascon JM. Nanomaterials for rechargeable lithium batteries. Angew Chem Int Ed, 2008, 47: 2930-2946

13 Gogotsi Y. What nano can do for energy storage. ACS Nano, 2014, 8: 5369-5371

14 Wang G, Zhang L, Zhang J. A review of electrode materials for electrochemical supercapacitors. Chem Soc Rev, 2012, 41: 797-828

15 Joshi RK, Schneider JJ. Assembly of one dimensional inorganic nanostructures into functional 2D and 3D architectures. Synthesis, arrangement and functionality. Chem Soc Rev, 2012, 41: 5285-5312

16 Chan CK, Peng H, Liu G, et al. High-performance lithium battery anodes using silicon nanowires. Nat Nanotechnol, 2008, 3: 31-35

17 Chabi S, Peng C, Hu D, et al. Ideal three-dimensional electrode structures for electrochemical energy storage. Adv Mater, 2014, 26: 2440-2445

18 Gao XP, Yang HX. Multi-electron reaction materials for high energy density batteries. Energy Environ Sci, 2010, 3: 174-189

19 Yang Q, Lu ZY, Liu JF, et al. Metal oxide and hydroxide nanoarrays: 
Hydrothermal synthesis and applications as supercapacitors and nanocatalysts. Prog Nat Sci: Mater Int, 2013, 23: 351-366

20 Yuan C, Wu HB, Xie Y, et al. Mixed transition-metal oxides: design, synthesis, and energy-related applications. Angew Chem Int Ed, 2014, 53: 1488-1504

21 Yuan CZ, Li JY, Hou LR, et al. Ultrathin mesoporous $\mathrm{NiCo}_{2} \mathrm{O}_{4}$ manosheets supported on $\mathrm{Ni}$ foam as advanced electrodes for supercapacitors. Adv Funct Mater, 2012, 22: 4592-4597

22 Zhu W, Lu ZY, Zhang GX, et al. Hierarchical $\mathrm{Ni}_{0.25} \mathrm{Co}_{0.75}(\mathrm{OH})_{2}$ nanoarrays for a high-performance supercapacitor electrode prepared by an in situ conversion process. J Mater Chem A, 2013, 1: 8327-8331

23 Xing W, Qiao S, Wu X, et al. Exaggerated capacitance using electrochemically active nickel foam as current collector in electrochemical measurement. J Power Sources, 2011, 196: 4123-4127

24 Xia XH, Tu JP, Zhang YQ, et al. High-quality metal oxide core/shell nanowire arrays on conductive substrates for electrochemical energy storage. ACS Nano, 2012, 6: 5531-5538

25 Dong $\mathrm{C}$, Wang $\mathrm{Y}, \mathrm{Xu}$ J, et al. 3D binder-free $\mathrm{Cu}_{2} \mathrm{O} @ \mathrm{Cu}$ nanoneedle arrays for high-performance asymmetric supercapacitors. J Mater Chem A, 2014, 2: 18229-18235

26 Li Y, Chang S, Liu X, et al. Nanostructured $\mathrm{CuO}$ directly grown on copper foam and their supercapacitance performance. Electrochim Acta, 2012, 85: 393-398

27 Lee SW, Kim BS, Chen S, et al. Layer-by-layer assembly of all carbon nanotube ultrathin films for electrochemical applications. J Am Chem Soc, 2009, 131: 671-679

$28 \mathrm{Lu} \mathrm{XH}$, Yu MH, Zhai T, et al. High energy density asymmetric quasi-solid-state supercapacitor based on porous vanadium nitride nanowire anode. Nano Lett, 2013, 13: 2628-2633

29 Yang P, Ding Y, Lin Z, et al. Low-cost high-performance solid-state asymmetric supercapacitors based on $\mathrm{MnO} 2$ nanowires and $\mathrm{Fe}_{2} \mathrm{O}$ nanotubes. Nano Lett, 2014, 14: 731-736

30 Xia X, Chao D, Fan Z, et al. A new type of porous graphite foams and their integrated composites with oxide/polymer core/shell nanowires for supercapacitors: structural design, fabrication, and full supercapacitor demonstrations. Nano Lett, 2014, 14: 1651-1658

31 Yang Y, Jeong S, Hu L, et al. Transparent lithium-ion batteries. Proc Natl Acad Sci USA, 2011, 108: 13013-13018

32 Yu G, Cao A, Lieber CM. Large-area blown bubble films of aligned nanowires and carbon nanotubes. Nat Nanotechnol, 2007, 2: 372377

33 Bai S, Sun C, Wan P, et al. Transparent conducting films of hierarchically nanostructured polyaniline networks on flexible substrates for high-performance gas sensors. Small, 2014, DOI: 10.1002/ smll.201401865

34 Ryu I, Yang $\mathrm{M}$, Kwon $\mathrm{H}$, et al. Coaxial $\mathrm{RuO}_{2}$-ITO nanopillars for transparent supercapacitor application. Langmuir, 2014, 30: 17041709

35 Hecht DS, Hu LB, Irvin G. Emerging transparent electrodes based on thin films of carbon nanotubes, graphene, and metallic nanostructures. Adv Mater, 2011, 23: 1482-1513

36 Duay J, Gillette E, Hu JK, et al. Controlled electrochemical deposition and transformation of hetero-nanoarchitectured electrodes for energy storage. Phys Chem Chem Phys, 2013, 15: 7976-7993

37 Su Z, Yan C, Tang D, et al. Fabrication of $\mathrm{Cu}_{2} \mathrm{ZnSnS}_{4}$ nanowires and nanotubes based on AAO templates. CrystEngComm, 2012, 14: 782-785

38 Liao Y, Que W, Zhong P, et al. A facile method to crystallize amorphous anodized $\mathrm{TiO}_{2}$ nanotubes at low temperature. ACS Appl Mater Interfaces, 2011, 3: 2800-2804

$39 \mathrm{Li}$ GR, Wang ZL, Zheng FL, et al. $\mathrm{ZnO} @ \mathrm{MoO}_{3}$ core/shell nanocables: facile electrochemical synthesis and enhanced supercapacitor performances. J Mater Chem, 2011, 21: 4217-4221

40 Pomfret MB, Brown DJ, Epshteyn A, et al. Electrochemical template deposition of aluminum nanorods using ionic liquids. Chem Mater, 2008, 20: 5945-5947

41 Fan ZJ, Yan J, Zhi LJ, et al. A three-dimensional carbon nanotube/ graphene sandwich and its application as electrode in supercapacitors. Adv Mater, 2010, 22: 3723-3728

42 Lu ZY, Yang Q, Zhu W, et al. Hierarchical $\mathrm{Co}_{3} \mathrm{O}_{4} @ \mathrm{Ni}-\mathrm{Co}-\mathrm{O}$ supercapacitor electrodes with ultrahigh specific capacitance per area. Nano Res, 2012, 5: 369-378

43 Yang Q, Lu ZY, Li T, et al. Hierarchical construction of core-shell metal oxide nanoarrays with ultrahigh areal capacitance. Nano Energy, 2014, 7: 170-178

44 Lu XH, Zheng DZ, Zhai T, et al. Facile synthesis of large-area manganese oxide nanorod arrays as a high-performance electrochemical supercapacitor. Energy Environ Sci, 2011, 4: 2915-2921

45 Xia XH, Tu JP, Zhang YQ, et al. Three-dimentional porous Nano- $\mathrm{Ni} / \mathrm{Co}(\mathrm{OH})_{2}$ nanoflake composite film: a pseudocapacitive material with superior performance. J Phys Chem C, 2011, 115: $22662-22668$

46 Lu ZY, Chang Z, Zhu W, et al. Beta-phased $\mathrm{Ni}(\mathrm{OH})_{2}$ nanowall film with reversible capacitance higher than theoretical Faradic capacitance. Chem Commun, 2011, 47: 9651-9653

47 Chen PC, Shen GZ, Shi Y, et al. Preparation and characterization of flexible asymmetric supercapacitors based on transition-metal-oxide nanowire/single-walled carbon nanotube hybrid thin-film electrodes. ACS Nano, 2010, 4: 4403-4411

48 Xu W, Lu Z, Lei X, et al. A hierarchical Ni-Co-O@Ni-Co-S nanoarray as an advanced oxygen evolution reaction electrode. Phys Chem Chem Phys, 2014, 16: 20402-20405

49 Yang TY, Kang HY, Jin K, et al. An iron oxide photoanode with hierarchical nanostructure for efficient water oxidation. J Mater Chem A, 2014, 2: 2297-2305

50 Yu LT, Jin YY, Li LL, et al. 3D porous gear-like copper oxide and their high electrochemical performance as supercapacitors. CrystEngComm, 2013, 15: 7657-7662

51 Lin YJ, Deng P, Nie YX, et al. Room-temperature self-powered ethanol sensing of a $\mathrm{Pd} / \mathrm{ZnO}$ nanoarray nanogenerator driven by human finger movement. Nanoscale, 2014, 6: 4604-4610

52 Yu XY, Lu ZY, Zhang GX, et al. $\mathrm{V}_{2} \mathrm{O}_{5}$ nanostructure arrays: controllable synthesis and performance as cathodes for lithium ion batteries. RSC Adv, 2013, 3: 19937-19941

53 Yang Q, Lu ZY, Chang Z, et al. Hierarchical $\mathrm{Co}_{3} \mathrm{O}_{4}$ nanosheet@ nanowire arrays with enhanced pseudocapacitive performance. RSC Adv, 2012, 2: 1663-1668

54 Liao JY, Lei BX, Chen H-Y, et al. Oriented hierarchical single crystalline anatase $\mathrm{TiO}_{2}$ nanowire arrays on Ti-foil substrate for efficient flexible dye-sensitized solar cells. Energy Environ Sci, 2012, 5: $5750-5757$

55 Wang J, Chao DL, Liu JL, et al. $\mathrm{Ni}_{3} \mathrm{~S}_{2} @ \mathrm{MoS}_{2}$ core/shell nanorod arrays on $\mathrm{Ni}$ foam for high-performance electrochemical energy storage. Nano Energy, 2014, 7: 151-160

56 Han LJ, Tang PY, Zhang L. Hierarchical $\mathrm{Co}_{3} \mathrm{O}_{4} @ P P y @ \mathrm{MnO}_{2}$ coreshell-shell nanowire arrays for enhanced electrochemical energy storage. Nano Energy, 2014, 7: 42-51

57 Luo QP, Lei BX, Yu XY, et al. Hiearchical ZnO rod-in-tube nano-architecture arrays produced via a two-step hydrothermal and ultrasonication process. J Mater Chem, 2011, 21: 8709-8714

$58 \mathrm{Wu} \mathrm{H}, \mathrm{Xu} \mathrm{M}$, Wang YC, et al. Branched $\mathrm{Co}_{3} \mathrm{O}_{4} / \mathrm{Fe}_{2} \mathrm{O}_{3}$ nanowires as high capacity lithium-ion battery anodes. Nano Res, 2013, 6: 167173

59 Zhang LL, Zhao XS. Carbon-based materials as supercapacitor electrodes. Chem Soc Rev, 2009, 38: 2520-2531

60 Zhai Y, Dou Y, Zhao D, et al. Carbon materials for chemical capacitive energy storage. Adv Mater, 2011, 23: 4828-4850

61 Candelaria SL, Shao YY, Zhou W, et al. Nanostructured carbon for energy storage and conversion. Nano Energy, 2012, 1: 195-220 
62 Largeot C, Portet C, Chmiola J, et al. Relation between the ion size and pore size for an electric double-layer capacitor. J Am Chem Soc, 2008, 130: 2730-2731

63 Jiang H, Lee PS, Li C. 3D carbon based nanostructures for advanced supercapacitors. Energy Environ Sci, 2013, 6: 41-53

64 Yan J, Wang Q, Wei T, et al. Recent advances in design and fabrication of electrochemical supercapacitors with high energy densities. Adv Energy Mater, 2014, 4: 1300816

65 Izadi-Najafabadi A, Yasuda S, Kobashi K, et al. Extracting the full potential of single-walled carbon nanotubes as durable supercapacitor electrodes operable at $4 \mathrm{~V}$ with high power and energy density. Adv Mater, 2010, 22: E235-241

66 Maiti UN, Lim J, Lee KE, et al. Three-dimensional shape engineered, interfacial gelation of reduced graphene oxide for high rate, large capacity supercapacitors. Adv Mater, 2014, 26: 615-619

67 Jiang J, Li YY, Liu JP, et al. Building one-dimensional oxide nanostructure arrays on conductive metal substrates for lithium-ion battery anodes. Nanoscale, 2011, 3: 45-58

68 Hochbaum AI, Yang PD. Semiconductor nanowires for energy conversion. Chem Rev, 2010, 110: 527-546

69 Lu ZY, Chang Z, Liu JF, et al. Stable ultrahigh specific capacitance of NiO nanorod arrays. Nano Res, 2011, 4: 658-665

70 Yang GW, Xu CL, Li HL. Electrodeposited nickel hydroxide on nickel foam with ultrahigh capacitance. Chem Commun, 2008, 48: 6537-6539

71 Peng X, Peng LL, Wu CZ, et al. Two dimensional nanomaterials for flexible supercapacitors. Chem Soc Rev, 2014, 43: 3303-3323

72 Yuan CZ, Yang L, Hou LR, et al. Growth of ultrathin mesoporous $\mathrm{Co}_{3} \mathrm{O}_{4}$ nanosheet arrays on $\mathrm{Ni}$ foam for high-performance electrochemical capacitors. Energy Environ Sci, 2012, 5: 7883-7887

73 Zhao GX, Li JX, Jiang L, et al. Synthesizing $\mathrm{MnO}_{2}$ nanosheets from graphene oxide templates for high performance pseudosupercapacitors. Chem Sci, 2012, 3: 433-437

74 Wang Q, O'Hare D. Recent advances in the synthesis and application of layered double hydroxide (LDH) nanosheets. Chem Rev, 2012, 112: 4124-4155

75 Zhao JW, Chen JL, Xu SM, et al. Hierarchical NiMn layered double hydroxide/carbon nanotubes architecture with superb energy density for flexible supercapacitors. Adv Funct Mater, 2014, 24: 2938 2946

76 Han JB, Dou YB, Zhao JW, et al. Flexible CoAl LDH@PEDOT core/shell nanoplatelet array for high-performance energy storage. Small, 2013, 9: 98-106

77 Jiang Z, Li ZP, Qin ZH, et al. LDH nanocages synthesized with MOF templates and their high performance as supercapacitors. Nanoscale, 2013, 5: 11770-11775

78 Ning FY, Shao MF, Zhang CL, et al. $\mathrm{Co}_{3} \mathrm{O}_{4} @$ layered double hydroxide core/shell hierarchical nanowire arrays for enhanced supercapacitance performance. Nano Energy, 2014, 7: 134-142

$79 \mathrm{Gu} \mathrm{YH,} \mathrm{Lu} \mathrm{ZY,} \mathrm{Chang} \mathrm{Z,} \mathrm{et} \mathrm{al.} \mathrm{NiTi} \mathrm{layered} \mathrm{double} \mathrm{hydroxide} \mathrm{thin}$ films for advanced pseudocapacitor electrodes. J Mater Chem A 2013, 1: 10655

80 Lu ZY, Zhu W, Lei XD, et al. High pseudocapacitive cobalt carbonate hydroxide films derived from CoAl layered double hydroxides. Nanoscale, 2012, 4: 3640-3643

81 Chen H, Hu LF, Chen M, et al. Nickel-cobalt layered double hydroxide nanosheets for high-performance supercapacitor electrode materials. Adv Funct Mater, 2014, 24: 934-942

82 Guan C, Liu JP, Cheng CW, et al. Hybrid structure of cobalt monoxide nanowire@ nickel hydroxidenitrate nanoflake aligned on nickel foam for high-rate supercapacitor. Energy Environ Sci, 2011, 4: 4496-4499

83 Zhou WJ, Cao XH, Zeng ZY, et al. One-step synthesis of $\mathrm{Ni}_{3} \mathrm{~S}_{2}$ nanorod@Ni(OH), nanosheet core-shell nanostructures on a threedimensional graphene network for high-performance supercapaci- tors. Energy Environ Sci, 2013, 6: 2216-2221

84 Lai XY, Halpert JE, Wang D. Recent advances in micro-/nano-structured hollow spheres for energy applications: from simple to complex systems. Energy Environ Sci, 2012, 5: 5604-5618

85 Guan C, Li X, Wang Z, et al. Nanoporous walls on macroporous foam: rational design of electrodes to push areal pseudocapacitance. Adv Mater, 2012, 24: 4186-4190

86 Yu GH, Xie X, Pan LJ, et al. Hybrid nanostructured materials for high-performance electrochemical capacitors. Nano Energy, 2013, 2: $213-234$

87 Liu JP, Jiang J, Cheng CW, et al. $\mathrm{Co}_{3} \mathrm{O}_{4}$ Nanowire@ $\mathrm{MnO}_{2}$ ultrathin nanosheet core/shell arrays: a new class of high-performance pseudocapacitive materials. Adv Mater, 2011, 23: 2076-2081

88 Yu L, Zhang G, Yuan C, et al. Hierarchical $\mathrm{NiCo}_{2} \mathrm{O}_{4} @ \mathrm{MnO}_{2}$ coreshell heterostructured nanowire arrays on $\mathrm{Ni}$ foam as high-performance supercapacitor electrodes. Chem Commun, 2013, 49: 137139

89 Yan J, Khoo E, Sumboja A, et al. Facile coating of manganese oxide on tin oxide nanowires with high-performance capacitive behavior. ACS Nano, 2010, 4: 4247-4255

90 Zhang GQ, Wu HB, Hoster $\mathrm{HE}$, et al. Single-crystalline $\mathrm{NiCo}_{2} \mathrm{O}$ nanoneedle arrays grown on conductive substrates as binder-free electrodes for high-performance supercapacitors. Energy Environ Sci, 2012, 5: 9453-9456

91 Mai LQ, Yang F, Zhao YL, et al. Hierarchical $\mathrm{MnMoO}_{4} / \mathrm{CoMoO}_{4}$ heterostructured nanowires with enhanced supercapacitor performance. Nat Commun, 2011, 2: 381

92 Liu JP, Jiang J, Bosman M, et al. Three-dimensional tubular arrays of $\mathrm{MnO}_{2}-\mathrm{NiO}$ nanoflakes with high areal pseudocapacitance. J Mater Chem, 2012, 22: 2419-2426

93 Aradilla D, Estrany F, Alemán C. Symmetric supercapacitors based on multilayers of conducting polymers. J Phys Chem C, 2011, 115: 8430-8438

94 Reddy ALM, Shaijumon MM, Gowda SR, et al. Multisegmented $\mathrm{Au}-\mathrm{MnO}_{2} /$ carbon nanotube hybrid coaxial arrays for high-power supercapacitor applications. J Phys Chem C, 2010, 114: 658-663

95 Xia $\mathrm{H}$, Meng YS, Yuan $\mathrm{G}$, et al. A Symmetric $\mathrm{RuO}_{2} \mathrm{RuO}_{2}$ supercapacitor operating at $1.6 \mathrm{~V}$ by using a neutral aqueous electrolyte. Electrochem Solid-State Lett, 2012, 15: A60-A63

96 Chen S, Zhu J, Wu X, et al. Graphene oxide- $\mathrm{MnO}_{2}$ nanocomposites for supercapacitors. ACS Nano, 2010, 4: 2822-2830

$97 \mathrm{Wu}$ ZS, Ren WC, Wang DW, et al. High-energy $\mathrm{MnO}_{2}$ nanowire/ graphene and graphene asymmetric electrochemical capacitors. ACS Nano, 2010, 4: 5835-5842

98 Yan J, Fan ZJ, Sun W, et al. Advanced asymmetric supercapacitors based on $\mathrm{Ni}(\mathrm{OH})_{2}$ /graphene and porous graphene electrodes with high energy density. Adv Funct Mater, 2012, 22: 2632-2641

99 Chen YC, Lin YG, Hsu YK, et al. Novel iron oxyhydroxide lepidocrocite nanosheet as ultrahigh power density anode material for asymmetric supercapacitors. Small, 2014, 10: 3803-3810

100 Long CL, Wei T, Yan J, et al. Supercapacitors based on graphene-supported iron nanosheets as negative electrode materials. ACS Nano, 2013, 7: 11325-11332

101 Zhou C, Zhang YW, Li YY, et al. Construction of high-capacitance 3D CoO@polypyrrole nanowire array electrode for aqueous asymmetric supercapacitor. Nano Lett, 2013, 13: 2078-2085

102 Cheng FY, Liang J, Tao ZL, et al. Functional materials for rechargeable batteries. Adv Mater, 2011, 23: 1695-1715

103 Wang H, Liang Y, Gong M, et al. An ultrafast nickel-iron battery from strongly coupled inorganic nanoparticle/nanocarbon hybrid materials. Nat Commun, 2012, 3: 917

104 Qu QT, Yang SB, Feng XL. 2D sandwich-like sheets of iron oxide grown on graphene as high energy anode material for supercapacitors. Adv Mater, 2011, 23: 5574-5580

105 Tang W, Zhu YS, Hou YY, et al. Aqueous rechargeable lithium bat- 
teries as an energy storage system of superfast charging. Energy Environ Sci, 2013, 6: 2093-2104

106 Tang W, Hou YY, Wang FX, et al. $\mathrm{LiMn}_{2} \mathrm{O}_{4}$ nanotube as cathode material of second-level charge capability for aqueous rechargeable batteries. Nano Lett, 2013, 13: 2036-2040

107 Tang W, Gao XW, Zhu YS, et al. A hybrid of $\mathrm{V}_{2} \mathrm{O}_{5}$ nanowires and MWCNTs coated with polypyrrole as an anode material for aqueous rechargeable lithium batteries with excellent cycling performance. J Mater Chem, 2012, 22: 20143-20145

$108 \mathrm{Wu}$ XC, Lu ZY, Zhu W, et al. High-performance aqueous battery with double hierarchical nanoarrays. Nano Energy, 2014, 10: 229234

109 Gong Y, Li J, Jiang PG, et al. Novel metal(II) coordination polymers based on N,N'-bis-(4-pyridyl)phthalamide as supercapacitor electrode materials in an aqueous electrolyte. Dalton Trans, 2013, 42: $1603-1611$
Acknowledgements This work was financially supported by the National Natural Science Foundation of China (21125101, 21271018), the National Basic Research Program of China (973 Program) (2011CBA00503 and 2011CB932403), the Program for New Century Excellent Talents in Universities, and the Program for Changjiang Scholars and Innovative Research Team in University.

Author contributions $\mathrm{Lu} \mathrm{Z,} \mathrm{Wu} \mathrm{X}$ and Sun X wrote the paper, Jiang M and Wang $\mathrm{J}$ searched and organized the references. All authors contributed to the general discussion.

Conflict of interest The authors declare that they have no conflict of interest.
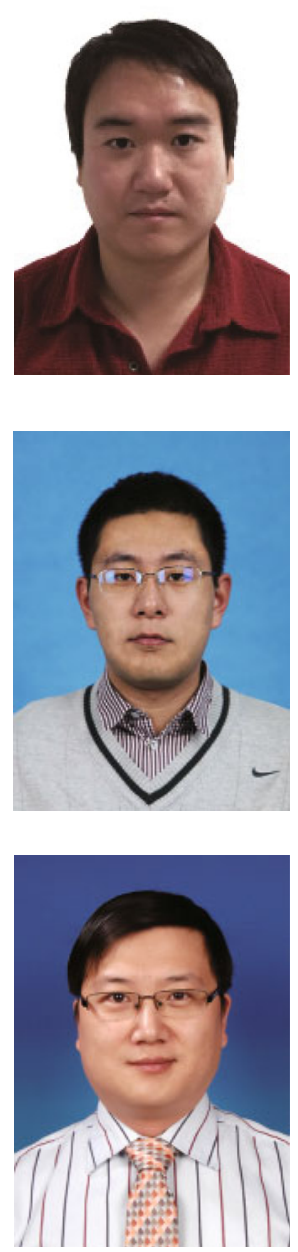

Zhiyi Lu was born in 1987. He is currently a PhD student at the State Key Laboratory of Chemical Resource Engineering, Beijing University of Chemical Technology. His research focuses on the synthesis and electrochemical applications of self-assembled inorganic materials in the solid-liquid interface.
Xiaochao Wu was born in 1989. He is currently a graduate student at the State Key Laboratory of Chemical Resource Engineering, Beijing University of Chemical Technology. His research interests focus on the application of transition metal oxide/hydroxide nanoarrays in supercapacitors and aqueous battery.

中文摘要 近几年来, 人们对于电化学储能设备的需求越来越多, 对它的高效性、安全性也越来越重视. 纳米阵列有序结构具有较大的 电化学活性比表面积, 快速的电子传输和离子扩散, 因此可以全面提高电极的比电容、倍率特性以及循环稳定性. 由于具有独特的结 构优势, 并可以有效地提高电化学储能效果, 纳米阵列有序结构成为了电极材料的新选择. 这篇综述总结了近些年来合成金属氧化物 或者氢氧化物纳米阵列有序结构材料的策略和方法, 以及在水相电解液中超级电容器和电池方面的应用. 